\title{
ANALISA DIMENSI, DENSITAS DAN KAPASITANSI SPESIFIK ELEKTRODA KARBON SUPERKAPASITOR DARI BUNGA RUMPUT GAJAH DENGAN VARIASI KONSENTRASI PENGAKTIVAN KOH
}

\author{
E.Taer ${ }^{1, a)}$, H.Yusra ${ }^{1, b)}$, Iwantono ${ }^{1}$, R.Taslim ${ }^{2}$ \\ ${ }^{1}$ Jurusan Fisika Universitas Riau, Pekanbaru 28293 \\ ${ }^{2}$ Jurusan Teknik Industri Universitas Islam Negeri Sultan Syarif Kasim, Pekanbaru $2829^{3}$

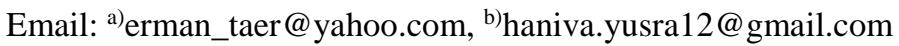

\begin{abstract}
Abstrak
Telah dilakukan analisa dimensi, densitas dan kapasitansi spesifik pada pembuatan elektroda karbon superkapasitor dari bunga rumput gajah menggunakan variasi konsentrasi aktivator $\mathrm{KOH}$. Pembuatan elektroda karbon diawali dengan proses prakarbonisasi, penggilingan dengan ball milling dan diayak dengan ukuran partikel $<53 \mu \mathrm{m}$. Proses berikutnya dilakukan aktivasi kimia menggunakan aktivator $\mathrm{KOH}$ dengan variasi konsentrasi sebesar 0,3 M, 0,5 M dan 0,7 M. Pelet karbon dibuat dengan alat hydraulic press pada tekanan 8 ton. Proses karbonisasi dilakukan pada suhu $600^{\circ} \mathrm{C}$ pada lingkungan gas $\mathrm{N}_{2}$ dengan profil pemanasan bertingkat, dan diikuti dengan proses aktivasi fisika menggunakan gas $\mathrm{CO}_{2}$ pada suhu $850^{\circ} \mathrm{C}$. Hasil penelitian ini diperoleh bahwa diameter, ketebalan dan massa setiap elektroda superkapasitor mengalami penurunan seiring dengan peningkatan konsentrasi KOH. Sedangkan densitas dan kapasitansi spesifik mengalami peningkatan dengan pertambahan konsentrasi KOH. Nilai kapasitansi spesifik tertinggi diperoleh sebesar $100,62 \mathrm{~F} / \mathrm{g}$ dengan densitas $0,87 \mathrm{gr} / \mathrm{cm}^{3}$ pada variasi 0,7 $\mathrm{M} \mathrm{KOH}$.
\end{abstract}

Kata-kata kunci: Analisa Dimensi, Kapasitansi Spesifik, Superkapasitor, Bunga Rumput Gajah, Variasi $\mathrm{KOH}$

\begin{abstract}
Dimensions, density and specific capacitance of carbon electrode supercapacitor from flower of elephant grass by using various $\mathrm{KOH}$ concentrations has been analyzed. Production of carbon electrodes was performed by pre-carbonization, grinding by ball milling and sieving to a find a particle size of $<53 \mu \mathrm{m}$. The following process was an activation by chemical activation using $\mathrm{KOH}$ by various concentrations of $0.3 \mathrm{M}, 0.5 \mathrm{M}$ and $0.7 \mathrm{M}$. Carbon pellets were produced by hydraulic press instrument at a pressure of 8 tons. Carbonization process was carried out at a temperature of $600^{\circ} \mathrm{C}$ in a $\mathrm{N}_{2}$ gas environment with multilevel heating profile, and followed by physical activation process by throwing $\mathrm{CO}_{2}$ gas at a temperature of $850^{\circ} \mathrm{C}$. The results of this study showed that the diameter, thickness and mass of each carbon electrode supercapacitor decrease with the increasing of $\mathrm{KOH}$ concentrations. While the density and specific capacitance were increased with the increasing of $\mathrm{KOH}$ concentrations. The highest specific capacitance value was obtained as high as $100.62 \mathrm{~F} / \mathrm{g}$ with a density of $0.87 \mathrm{~g} / \mathrm{cm}^{3}$ in the variation of $0.7 \mathrm{M} \mathrm{KOH}$.

Keywords: Dimensional Analysis, Specific Capacitance, Supercapacitors, Flower Elephant Grass,
\end{abstract} Variations $\mathrm{KOH}$ 


\section{PENDAHULUAN}

Superkapasitor merupakan alat penyimpan energi yang memiliki nilai kapasitansi tinggi dibandingkan dengan kapasitor biasa. Superkapasitor terdiri dari pengumpul arus, elektroda karbon, separator dan elektrolit.

Bahan karbon banyak digunakan sebagai bahan pembuatan elektroda superkapasitor karena luas permukaan yang tinggi, biaya yang rendah dan mudah didapat [1]. Elektroda karbon pada superkapasitor dapat dibuat dari bahan biomassa yang memiliki kandungan karbon yang tinggi. Salah satu biomassa yang dapat digunakan adalah bunga rumput gajah. Bunga rumput gajah memiliki struktur yang ringan dan lembut sehingga dapat mudah dihancurkan menjadi partikel yang sangat halus [2]. Pelet karbon dapat dicetak dari partikel bunga rumput gajah yang sudah halus.

Pengaktivan kimia menggunakan $\mathrm{KOH}$ bertujuan untuk memperbesar luas permukaan karbon dengan membuka pori-pori yang tertutup sehingga memperbesar daya serapnya. Berdasarkan hasil penelitian proses aktivasi menggunakan kalium hidroksida $(\mathrm{KOH})$ menghasilkan karbon aktif dengan luas permukaan mencapai $3000 \mathrm{~m}^{2} \mathrm{~g}^{-1}$ [3] dan $2202 \mathrm{~m}^{2} \mathrm{~g}^{-1}$ [4]. Besarnya konsentrasi aktivator $\mathrm{KOH}$ sangat berpengaruh terhadap ukuran dan struktur pori karbon. Perbedaan konsentrasi tersebut juga berpengaruh terhadap nilai dimensi, densitas dan kapasitansi spesifik suatu karbon aktif.

\section{METODE PENELITIAN}

Pembuatan superkapasitor dimulai dari pengumpulan bahan dasar elektroda karbon superkapasitor dari bunga rumput gajah. Bunga rumput gajah dikeringkan dan dilakukan proses pra-karbonisasi pada suhu $250^{\circ} \mathrm{C}$ selama 2,5 jam. Proses selanjutnya sampel dihaluskan dengan hard grinder dan diikuti dengan penggilingan menggunakan ball milling selama 20 jam untuk memperoleh partikel yang sangat halus. Lalu dilakukan pengayakan dengan ayakan berukuran $53 \mu \mathrm{m}$ untuk memperoleh ukuran partikel yang lebih kecil dari $53 \mu \mathrm{m}$. Proses aktivasi kimia dilakukan menggunakan aktivator $\mathrm{KOH}$ dengan variasi $0,3 \mathrm{M}, 0,5 \mathrm{M}$ dan 0,7 M. Sampel yang telah diaktivasi kimia lalu dinetralkan dan dikeringkan kedalam oven suhu $110^{\circ} \mathrm{C}$ selama satu minggu hingga kering. Sampel yang sudah kering lalu dihaluskan kembali dan ditimbang $0,7 \mathrm{~g}$ sebanyak 10 sampel pada masing-masing variasi untuk dicetak menjadi pelet. Proses pencetakan menggunakan alat hydraulic press pada tekanan 8 ton.

Proses karbonisasi dilakukan dengan furnance pada suhu $600^{\circ} \mathrm{C}$ dalam lingkungan gas $\mathrm{N}_{2}$ lalu diikuti dengan proses aktivasi fisika pada suhu $850^{\circ} \mathrm{C}$ dalam lingkungan gas $\mathrm{CO}_{2}$. Pengukuran dimensi yang dilakukan meliputi pengukuran ketebalan, diameter dan massa dari tiap tiap pelet setelah dilakukan aktivasi fisika pada masing masing variasi. Densitas dapat dihitung dengan rumus:

$$
\rho=\frac{m}{V}
$$

dimana $\rho$ adalah densitas, $m$ adalah massa dan $V$ adalah volume pelet karbon.

Sampel pelet karbon yang telah dilakukan pengukuran densitas lalu dipoles menggunakan kertas pasir konveks P1200. Pemolesan bertujuan untuk mendapatkan permukaan pelet yang halus dan memiliki massa $0,025 \mathrm{~g}-0,030 \mathrm{~g}$. Pelet karbon yang telah dipoles digunakan untuk proses pengukuran kapasitansi spesifik sel superkapasitor menggunakan metode Cyclic Voltametry $(C V)$. Sebelum dilakukan pengukuran sampel direndam dengan elektrolit $\mathrm{H}_{2} \mathrm{SO}_{4} 1 \mathrm{M}$ selama $24 \mathrm{jam}$.

Sel superkapasitor dibuat dengan susunan yang terdiri dari teflon, pengumpul arus, separator dan elektroda karbon aktif dari bunga rumput gajah. Setelah itu nilai kapasitansi spesifik sel superkapasitor dapat dihitung menggunakan metoda $C V$ pada laju imbasan $1 \mathrm{mV} / \mathrm{s}$. Kapasitansi spesifik dapat dihitung menggunakan persamaan berikut [5]:

$$
C_{s p}=\frac{2\left[I_{c}-\left[-I_{d}\right] / 2\right]}{s \times m}
$$

dimana $C_{s p}$ merupakan kapasitansi spesifik, $I_{c}$ adalah arus masuk, $I_{d}$ adalah arus keluar, $s$ adalah laju imbasan dan $m$ adalah massa elektroda karbon aktif. 


\section{HASIL DAN PEMBAHASAN}

\subsection{Dimensi dan Densitas}

Pengukuran dimensi pelet karbon bunga rumput gajah yang dilakukan meliputi pengukuran diameter, ketebalan dan massa setiap pelet pada masing-masing variasi. Pengukuran dilakukan setelah proses aktivasi fisika. Adapun nilai rata-rata hasil pengukuran dimensi tersebut ditunjukkan pada Tabel 1.

Tabel 1. Data hasil pengukuran dimensi.

\begin{tabular}{|c|c|c|c|}
\hline Konsentrasi KOH & Diameter $(\mathrm{mm})$ & Ketebalan $(\mathrm{mm})$ & Massa $(\mathrm{gr})$ \\
\hline $0,3 \mathrm{M}$ & 14,926 & 1,447 & 0,206 \\
\hline $0,5 \mathrm{M}$ & 14,186 & 1,42 & 0,191 \\
\hline $0,7 \mathrm{M}$ & 14,544 & 1,393 & 0,199 \\
\hline
\end{tabular}

Diameter, ketebalan dan massa pelet karbon pada variasi tertinggi memiliki nilai yang lebih kecil dibandingkan dengan variasi konsentrasi $\mathrm{KOH}$ yang terendah. Hal ini akan berpengaruh terhadap nilai densitas yang akan dihasilkan. Adapun hasil pengukuran densitas berdasarkan data hasil pengukuran dimensi pada masing-masing variasi konsentrasi KOH ditunjukkan pada Tabel 2.

Tabel 2. Data hasil pengukuran densitas

\begin{tabular}{|c|c|}
\hline Konsentrasi $\mathrm{KOH}$ & Densitas $\left(\mathrm{gr} / \mathrm{cm}^{3}\right)$ \\
\hline $0,3 \mathrm{M}$ & 0,818 \\
\hline $0,5 \mathrm{M}$ & 0,846 \\
\hline $0,7 \mathrm{M}$ & 0,876 \\
\hline
\end{tabular}

Perbedaan nilai densitas yang ditunjukkan pada Tabel 2 dapat dijelaskan sebagai berikut. Penambahan molaritas KOH menyebabkan partikel-partikel menjadi lebih kecil dan pori yang lebih banyak sehingga menyebabkan pembentukan mikropori yang lebih dominan [6]. Pencetakan pelet membuat partikel lebih teratur sehingga untuk pelet karbon dengan nilai konsentrasi $\mathrm{KOH}$ tinggi menjadi lebih padat karena partikelnya lebih halus setelah aktivasi sehingga menghasilkan nilai densitas yang lebih tinggi. Sedangkan pelet karbon dengan konsentrasi $\mathrm{KOH}$ rendah memiliki ukuran partikel setelah aktivasi kimia lebih besar sehingga menghasilkan pelet yang kurang padat dan densitas rendah. Oleh karena itu variasi konsentrasi $\mathrm{KOH} \mathrm{0,3} \mathrm{M} \mathrm{menghasilkan} \mathrm{pelet} \mathrm{dengan} \mathrm{densitas}$ yang lebih rendah dibandingkan dengan konsentrasi $\mathrm{KOH} \mathrm{0,5} \mathrm{M}$ dan 0,7 $\mathrm{M}$.

Pada Tabel 1 terlihat bahwa diameter, ketebalan dan massa pelet dari masing-masing variasi mengalami penurunan seiring dengan pertambahan konsentrasi $\mathrm{KOH}$. Hal ini menyebabkan nilai densitas dari pelet karbon mengalami kenaikan seiring dengan pertambahan konstentrasi $\mathrm{KOH}$.

\subsection{Kapasitansi Spesifik}

Pengukuran nilai kapasitansi spesifik dilakukan menggunakan metode Cyclic Voltametry (CV) menggunakan alat Physics CV UR Rad-Er 5841 dengan laju imbasan $1 \mathrm{mV} / \mathrm{s}$ pada jendela potensial $0 \mathrm{mV}$ $500 \mathrm{mV}$. 


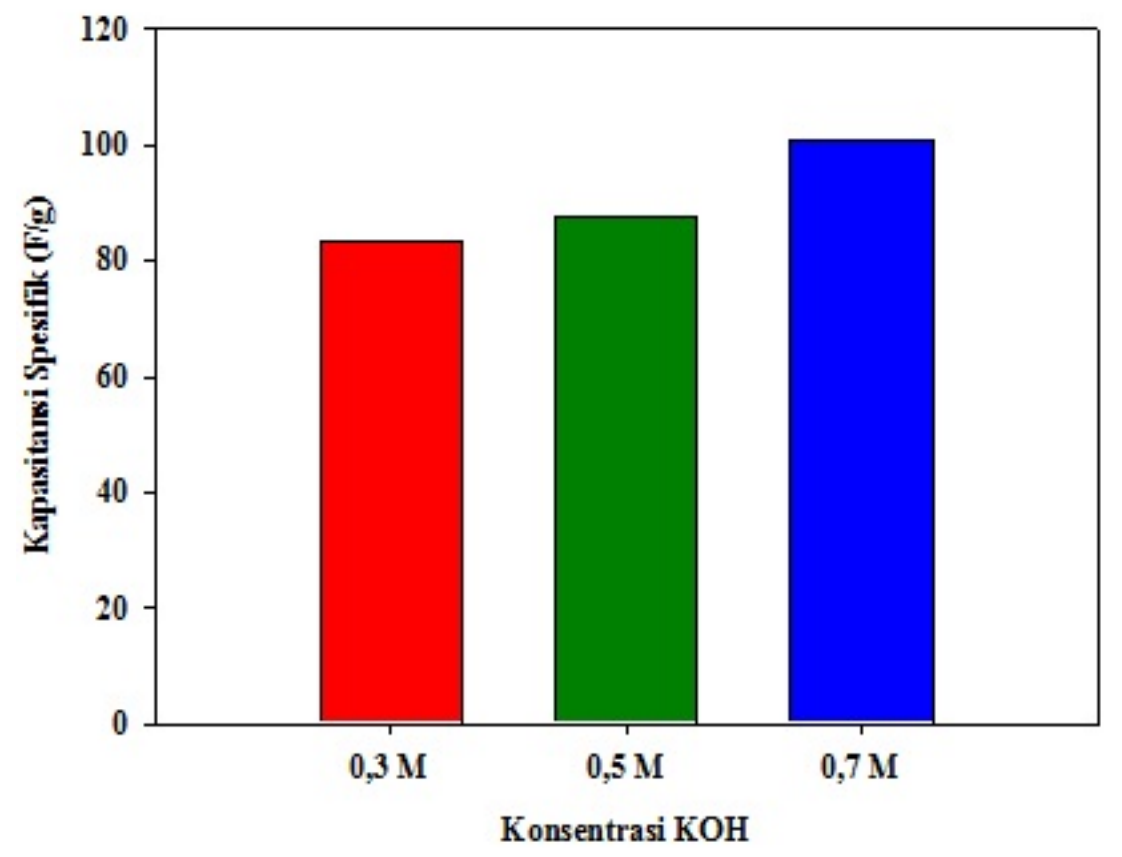

Gambar 1. Diagram perbandingan nilai kapasitansi spesifik berdasarkan variasi aktivator KOH.

Pengukuran CV ini dilakukan sebanyak dua kali pengujian. Nilai rata-rata kapasitansi spesifik dari hasil pengukuran tersebut dapat dilihat pada Gambar 1. Terlihat bahwa nilai kapasitansi spesifik mengalami kenaikan seiring bertambahnya konsentrasi $\mathrm{KOH}$ yang diberikan. Berdasarkan data hasil perhitungan menggunakan persamaan (2) didapatkan nilai kapasitansi spesifik pada konsentrasi 0,3 M, 0,5 M dan 0,7 M yaitu sebesar 83,26 F/g, 87,7 F/g dan 100,62 F/g. Terdapat perbedaan nilai kapasitansi spesifik disetiap variasi dimana nilai kapasitansi spesifik tertinggi didapatkan pada variasi konsentrasi $0,7 \mathrm{M} \mathrm{KOH}$.

Pada penelitian ini terlihat bahwa penggunaan karbon bunga rumput gajah memiliki potensi yang baik sebagai bahan dasar elektroda karbon aktif sel superkapasitor. Penggunaan elektroda karbon aktif dengan bahan pengaktif $0,3 \mathrm{M}, 0,5 \mathrm{M}$ dan $0,7 \mathrm{M}$ berpengaruh terhadap nilai densitas pelet karbon dan kapasitansi spesifik karbon tersebut. Hasil penelitian menunjukkan bahwa nilai densitas dan kapasitansi spesifik akan mengalami peningkatan seiring dengan bertambahnya nilai konsentrasi $\mathrm{KOH}$ yang diberikan pada elektroda karbon.

\section{SIMPULAN}

Analisa dimensi, densitas dan kapasitansi spesifik pada elektroda karbon superkapasitor bunga rumput gajah berdasarkan variasi konsentrasi $\mathrm{KOH}$ telah berhasil dilakukan. Ketebalan, diameter dan massa pelet elektroda karbon mengalami penurunan hal ini menyebabkan nilai densitas pelet elektroda karbon mangalami kenaikan seiring dengan bertambahnya konsentrasi $\mathrm{KOH}$ yang diberikan. Nilai densitas tertinggi diperoleh pada konsentrasi $0,7 \mathrm{M} \mathrm{KOH}$ yaitu sebesar $0,876 \mathrm{gr} / \mathrm{cm}^{3}$.

Setelah dilakukan pengukuran Cyclic Voltametry diperoleh nilai kapasitansi spesifik tertinggi pada variasi 0,7 M yaitu sebesar 100,62 F/g. Bertambahnya nilai konsentrasi yang diberikan makan akan semakin tinggi nilai densitas pelet karbon dan kapasitansi spesifiknya.

\section{UCAPAN TERIMAKASIH}

Penulis mengucapkan terimakasih kepada penyokong dana penelitian yaitu proyek HIKOM tahun 2016 yang diberikan kepada peneliti utama Dr. Erman Taer, M.Si. 


\section{DAFTAR ACUAN}

[1] V. Ruiz, C. Blanco, M. Granda, R. Menendez, and R. Santamaria, "Influence of electrode preparation on the electrochemical behaviour of carbon-based supercapacitors", J Appl Electrochem 37, 2007, pp. 717-721.

[2] E. Taer, H. Halim, R. Farma, R. Taslim, "Karakterisasi partikel pra-karbon dari bunga rumput gajah (Pennisetum polystachyon) dengan campuran surfaktan anionik sodium dodesil sulfat sebagai bahan dasar superkapasitor", Prosiding Seminar Nasional Fisika UNJ IV, 2015, pp. 67-70.

[3] H. Teng, L.Y. Hsu, "High Porosity Carbons Prepared from Bituminous Coal with Pottasium Hydroxide Activation”, Ind. Eng. Chem. Res 38,1999, pp. 2947-2953.

[4] J.S. Nazzal, W. Kaminska, B. Michalkiewicz, dan Z.C. Koren, "Production, characterization and methane storage potential of $\mathrm{KOH}$-activated carbon from sugarcane molasses", Industrial Crops and Products 47,2013, pp. 153- 159.

[5] D. Kalpana, S.H. Cho, S.B. Lee, Y.S. Lee, R. Misra, "Recycled waste paper A new source of raw material for electric double layer capacitors", Journal of Power Sources 19,2009, pp. 587-591.

[6] A.G. Pandolfo, A.F. Hollenkamp, "Carbon properties and their role in superkapacitors," Journal of Power Sources 157,2006, pp. 11-27. 
